\title{
MODELING THE CORRELATION BETWEEN HEAT TREATMENT, CHEMICAL COMPOSITION AND BAINITE FRACTION OF PIPELINE STEELS BY MEANS OF ARTIFICIAL NEURAL NETWORKS
}

Gholamreza Khalaj, Hesam Pouraliakbar, Kaveh Rahimi Mamaghani Mohammad-Javad Khalaj

\begin{abstract}
In the present study, bainite fraction results of continuous cooling of high strength low alloy steels have been modeled by artificial neural networks. The artificial neural network models were constructed by 16 input parameters including chemical compositions (C, Mn, Nb, Mo, Ti, N, Cu, P, S, Si, Al, V), Nb in solution, austenitizing temperature, initial austenite grain size and cooling rate over the temperature range of the occurrence of phase transformations. The value for the output layer was the bainite fraction. According to the input parameters in feed-forward back-propagation algorithm, the constructed networks were trained, validated and tested. To make a decision on the completion of the training processes, two termination states are declared: state 1 (ANN-I model) means that the training of neural network was ended when the maximum epoch of process reached (1000) while state 2 (ANN-II model) means the training ended when minimum error norm of network gained. The entire statistical evaluators of ANN-II model has higher performance than those of ANN-I. However, both of the models exhibit valuable results and the entire statistical values show that the proposed ANN-I and ANN-II models are suitably trained and can predict the bainite fraction values very close to the experimental ones.
\end{abstract}

Key words: ANN, HSLA, pipeline steel, microalloyed steel, bainite transformation Received: June 29, 2013

Revised and accepted: September 5, 2013

*Gholamreza Khalaj, Mohammad-Javad Khalaj Department of Engineering, Saveh Branch, Islamic Azad University, Saveh, Iran, E-mail: gh.khalaj@srbiau.ac.ir, Fax: +98 8642433008

†Hesam Pouraliakbar

Department of Materials Science and Engineering, Sharif University of Technology, Tehran, Iran Department of Advanced Materials, WorldTech Scientific Research Center (WT-SRC), Tehran, Iran

$\ddagger$ Kaveh Rahimi Mamaghani

Department of Materials Science and Engineering, Sharif University of Technology, Tehran, Iran Department of Materials Processing, WorldTech Scientific Research Center (WT-SRC), Tehran, Iran

(c) CTU FTS 2013 


\section{Introduction}

High Strength Low Alloy (HSLA) steels were developed by combining the benefits of precipitation hardening of microalloying elements with the advantages of grain refinement. Controlled rolling and accelerated controlled cooling are the two common processing routes of HSLA steels [1]. A complex chemistry plus complicated thermomechanical processing have led to the introduction of the most advanced steel in this class, X 100 grade steels with a tensile strength of more than $800 \mathrm{MPa}$ for pipeline applications [2]. Austenite decomposition during cooling on the run-out table is of critical importance considering its influence on the final microstructure and mechanical properties of steel. Austenite decomposition in steel has been investigated extensively in the last 50-60 years and a good summary on experimental observations of austenite decomposition was provided by Zhao and Notis [3].

Depending on the cooling rate, initial austenite grain size, deformation condition and alloy addition, various transformation products can form through different types of transformation mechanisms (as an example, diffusional and displacive transformation mechanisms) [4]. Polygonal ferrite (PF), acicular ferrite $(\mathrm{AF})$, pearlite $(\mathrm{P})$, bainite $(\mathrm{B})$ and lath martensite $(\mathrm{LM})$ are the main transformed products reported for hot rolled low $\mathrm{C}$ and microalloyed steels after austenite decomposition.

Bainite transformation occurs in a temperature range, i.e. $\sim 250-600^{\circ} \mathrm{C}$, below that of pearlite and is characterized classically by a non-lamellar mixture of ferrite laths and a carbide phase where the later forms from carbon enriched residual austenite usually as cementite [5]. The mechanism of bainite transformation has been an area of much debate and controversy for a number of years, continuing into the present time, from which different view points on the mechanism of transformation have emerged [5-8].

Hot strip rolling of modern micro-alloyed AHSS is expected to produce a final microstructure that consists of primarily fine ferrite, bainite and martensite after austenite decomposition [9-10]. The start temperature for bainite is generally presented as chemistry dependent, i.e. the bainite formation shifts to lower temperature with increasing carbon content or carbon equivalent [11-12]. Rees et al. [13] investigated the effect of alloying elements on the bainite transformation temperature. Their work on low carbon $\mathrm{Nb}$ microalloyed steel with varying $\mathrm{Nb}$ contents (0.001- $0.035 \mathrm{wt} \%$ ), showed that similar to polygonal ferrite, bainite transformation is retarded with increasing $\mathrm{Nb}$ content in solution. Their study [13] also revealed that the initial austenite grain size has negligible effects on the bainite formation. The growth of bainite is still a subject of immense debate. A number of theories have been proposed for bainite formation kinetics and they are mainly classified as, either diffusional or displacive approaches $[11,14,15]$. In addition to diffusive and displacive approaches, the JMAK approach has also been employed to describe the bainite formation kinetics [16-18].

Recently, with the arrival of new advanced steel products consisting of a multiphase microstracture, it is important to develop modelling approaches that can describe the simultaneous formation of more than one transformation product. Relatively, few studies have been proposed to capture the overall decomposition of austenite to various transformed products such as ferrite, pearlite, bainite and 
Khalaj G. et al.: Modeling the correlation between heat treatment, chemical...

martensite under industrial cooling conditions. Separate work by Umemoto [19], Bhadeshia [20], Minote et al. [21], Samoilov [22] and Liu et al. [23], used the JMAK law to describe austenite decomposition to ferrite and pearlite and the required modifications were made to capture the simultaneous reactions, i.e. either diffusional or displacive approaches were proposed to describe the bainite formation. Most of these models had originally been developed for the isothermal transformation condition, but then extended to the continuous cooling condition.

Artificial neural networks (ANNs) are a family of massively parallel architectures that solve difficult problems via the cooperation of highly interconnected but simple computing elements (or artificial neurons). Basically, the processing elements of a neural network are analogous to the neurons in the brain, which consist of many simple computational elements arranged in several layers. ANNs have been applied for prediction different properties of different type of steels in the previous works [24-27].

In authors' previous work $[28,29]$ the effects of chemical composition, austenitizing temperature, $\mathrm{Nb}$ in solution, austenitic grain size and cooling rate on Vickers microhardness and ferrite fraction of microalloy steels modeled with the artificial neural networks (ANNs). As authors' literature survey, there is no work investigating the effects of chemical compositions, austenitizing temperature, $\mathrm{Nb}$ in solution, austenite grain size and cooling rate on bainite fraction of microalloy steels.

The objective of the present work is to describe the austenite to bainite phase transformation behaviour of the five HSLA steels under continuous cooling conditions in the cooling rates regime of " $0.3-198^{\circ} \mathrm{C} / \mathrm{s} "$ with various initial austenite grain structures and different austenitizing temperatures. Totally 104 bainite fraction data were collected from the literature, trained, tested and validated by neural network. The obtained results were compared by experimental ones to evaluate the software power for predicting the effects of mentioned parameters on bainite fraction of the studied steels.

\section{Artificial neural networks}

ANNs were developed to model the human brain. Even an ANN fairly simple and small in size when compared to the human brain, has some powerful characteristics in knowledge and information processing because of its similarity to the human brain. Therefore, an ANN can be a powerful tool for engineering applications [30]. McCulloch and Pitts [31] defined artificial neurons for the first time and developed a neuron model. McCulloch and Pitts' network [31] formed the basis for almost all later neural network models. Afterwards, Rosenblatt devised a machine called the perceptron that operated much in the same way as the human mind [32]. Rosenblatt's perceptrons consist of "sensory" units connected to a single layer of McCulloch and Pitts [32] neurons. Rumelhardt et al. derived a learning algorithm for perceptron networks with constituted hidden units [33]. Their learning algorithm is called back-propagation and is now the most widely used learning algorithm. As a result of these studies, together with the developments in computer technology, using ANN has become more efficient after 1980 [33].

An artificial neuron is composed of five main parts: inputs, weights, sum function, activation function and outputs. Inputs are information that enters the neuron 
from other neurons of from external world. Weights are values that express the outcome of an input set or another process element in the preceding layer on this process element. Sum function is a function that calculates the effect of inputs and weights completely on this process element. This function computes the net input that approaches to a neuron [34]. The weighted sums of the input components (net) ${ }_{j}$ are calculated using Eq. (1) as follows:

$$
(\text { net })_{j}=\left(\sum_{i=1}^{n} w_{i j} x_{i}\right)+b
$$

where $(n e t)_{j}$ is the weighted sum of the $j^{\text {th }}$ neuron for the input received from the preceding layer with $\mathrm{n}$ neurons, $W_{i j}$ is the weight between the $j$ th neuron in the previous layer, $\mathrm{x}_{i}$ is the output of the $i$ th neuron in the previous layer [33]. $b$ is a fix value as internal addition and $\sum$ represents sum function. Activation function is a function that processes the net input obtained from sum function and determines the neuron output. In general for multilayer feed-forward models as the activation function sigmoid activation function is used. The output of the $j^{\text {th }}$ neuron $(o u t)_{j}$ is computed using Eq. (2) with a sigmoid activation function as follows [33]:

$$
O_{j}=f(n e t)_{j}=\frac{1}{1+e^{-\alpha(n e t)_{j}}}
$$

where $\alpha$ is constant used to control the slope of the semi-linear region. The sigmoid nonlinearity activates in every layer except in the input layer [33]. The sigmoid activation function represented by Eq. (2) gives outputs in $(0,1)$. If it desired, the outputs of this function can be adjusted to $(-1,1)$ interval. As the sigmoid processor represents a continuous function it is particularly used in non-linear descriptions. Because its derivatives can be determined easily with regard to the parameters within $(\text { net })_{j}$ variable [33].

\section{Data collection}

In the present investigation, the artificial neural network has been trained, tested and validated for prediction bainite fraction of HSLA steels. For this purpose, the experimental data of five HSLA steels with different chemical compositions have been used [34-38]. The chemical compositions of these steels are summarized in Tab. I. The input variables of the ANN modeling are the weight percent of alloying elements, austenitizing temperature, $\mathrm{Nb}$ in solution, austenite grain size and cooling rate. These parameters along with their ranges have been summarized in Tab. II.

Employing appropriate thermal cycles, continuous cooling transformation (CCT) tests were conducted to examine the effect of chemical compositions, niobium condition, austenitizing temperature, austenite grain size and cooling rate on austenite decomposition behavior of the steels. The resulting microstructures, which usually consist of ferrite, bainite and martensite- austenite (MA) constituents, were examined using optical microscopy. They were revealed using appropriate etchants and the corresponding phase volume fractions were subsequently measured in accordance with ASTM standards. To consider the significant effect of the niobium 
Khalaj G. et al.: Modeling the correlation between heat treatment, chemical...

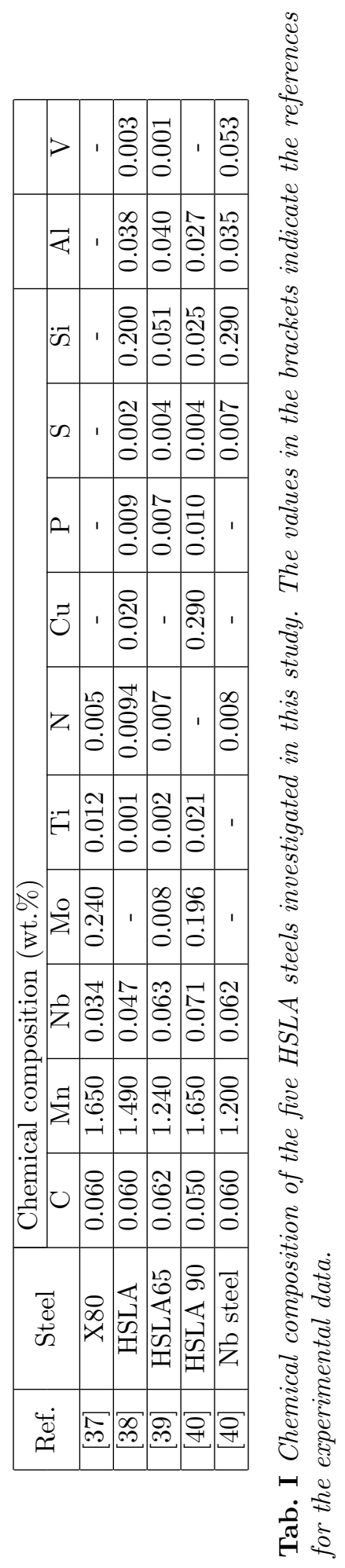


Neural Network World 4/13, 351-367

\begin{tabular}{|c|c|c|c|c|c|}
\hline Parameter & & Minimum & Maximum & Mean & $\begin{array}{l}\text { Standard } \\
\text { deviation }\end{array}$ \\
\hline \multicolumn{6}{|l|}{ Input } \\
\hline $\mathrm{C}$ & wt\% & 0.05 & 0.062 & 0.058788 & 0.004128 \\
\hline $\mathrm{Mn}$ & wt\% & 1.2 & 1.65 & 1.485 & 0.179919 \\
\hline $\mathrm{Nb}$ & wt\% & 0.034 & 0.071 & 0.052279 & 0.014134 \\
\hline Mo & wt\% & 0 & 0.24 & 0.105231 & 0.111022 \\
\hline $\mathrm{Ti}$ & wt\% & 0 & 0.021 & 0.007846 & 0.007624 \\
\hline $\mathrm{N}$ & wt\% & 0 & 0.0094 & 0.005818 & 0.003118 \\
\hline $\mathrm{Cu}$ & wt\% & 0 & 0.29 & 0.054808 & 0.108431 \\
\hline $\mathrm{P}$ & wt\% & 0 & 0.01 & 0.005625 & 0.004153 \\
\hline S & wt\% & 0 & 0.007 & 0.002529 & 0.001961 \\
\hline $\mathrm{Si}$ & wt\% & 0 & 0.29 & 0.077663 & 0.090021 \\
\hline $\mathrm{Al}$ & wt\% & 0 & 0.04 & 0.02551 & 0.016902 \\
\hline V & wt\% & 0 & 0.053 & 0.0035 & 0.011241 \\
\hline Nbs & & 0 & 1 & - & - \\
\hline $\mathrm{AT}$ & ${ }^{\circ} \mathrm{C}$ & 800 & 950 & 908.1731 & 61.97031 \\
\hline $\mathrm{D} \gamma$ & $\mu \mathrm{m}$ & 5 & 130 & 40.51923 & 35.52901 \\
\hline CR & ${ }^{\circ} \mathrm{C} / \mathrm{s}$ & 0.3 & 198 & 42.92596 & 48.42347 \\
\hline \multicolumn{6}{|l|}{ Output } \\
\hline $\mathrm{Bf}$ & \%vol & 0 & 100 & 53.26442 & 36.64391 \\
\hline
\end{tabular}

Tab. II The range of the input and output parameters in ANN models.

solid solution level on the transformation of austenite, two thermal histories were developed. For the first case, $\mathrm{Nb}$ was dissolved in solid solution prior to austenite decomposition. In contrast, the second scenario involved the formation of $\mathrm{Nb}(\mathrm{C}, \mathrm{N})$ precipitates prior to austenite decomposition, i.e. leaving a low level of $\mathrm{Nb}$ in solid solution.

\section{Artificial neural networks parameters and structure}

ANN model in this research has sixteen neurons in the input layer and one neurons in the output

layer as demonstrated in Fig. 1. The values for input layers were carbon weight percent $(\mathrm{C})$, manganese weight percent $(\mathrm{Mn})$, niobium weight percent $(\mathrm{Nb})$, molybdenum weight percent (Mo), titanium weight percent (Ti), nitrogen weight percent $(\mathrm{N})$, copper weight percent $(\mathrm{Cu})$, phosphorous weight percent $(\mathrm{P})$, sulfur weight percent $(\mathrm{S})$, silicon weight percent $(\mathrm{Si})$, aluminum weight percent $(\mathrm{Al})$, vanadium weight percent $(\mathrm{V}), \mathrm{Nb}$ in solution (Nbs), austenitizing temperature $(\mathrm{AT})$, the initial austenite grain size $(\mathrm{D} \gamma)$ and the cooling rate $(\mathrm{CR})$.

The value for output layer was bainite fraction $(\mathrm{Bf})$. The range of the input and output parameters has been illustrated in Tab. II. Two hidden layer with ten and eight neurons were used in the architecture of multilayer neural network because 
Khalaj G. et al.: Modeling the correlation between heat treatment, chemical...

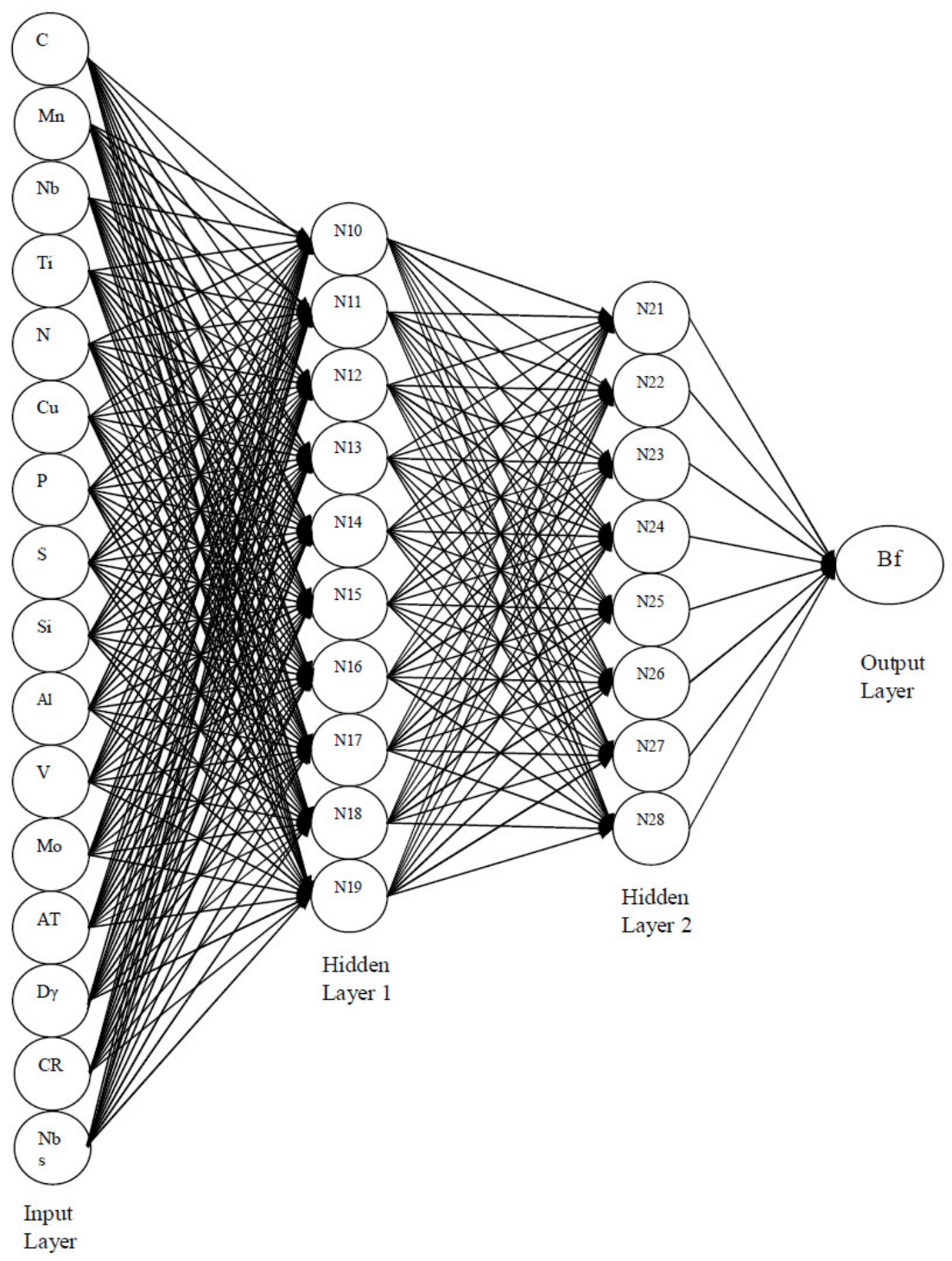

Fig. 1 The system used in the ANN model.

of its minimum absolute percentage error values for training and testing sets. The neurons of neighboring layers are completely interconnected by weights. Finally, the output layer neurons produce the network prediction as a result.

In this study, the back-propagation training algorithm has been utilized in feedforward two hidden layers. Back-propagation algorithm, as one of the most wellknown training algorithms for the multilayer perceptron, is a gradient descent technique to minimize the error for a particular training pattern in which it adjust the weights by a small amount at a time [33]. The non-linear sigmoid activa- 
tion function was used in the hidden layer and the neuron outputs at the output layer. Momentum rate and learning rate values were determined and the model was trained through iterations. The trained model was only tested with the input values and the predicted results were close to experiment results. The values of parameters used in neural network model are given in Tab. III.

\begin{tabular}{|l|l|}
\hline Parameters & ANN \\
\hline Number of input layer units & 16 \\
\hline Number of hidden layer & 2 \\
\hline Number of first hidden layer units & 10 \\
\hline Number of second hidden layer units & 8 \\
\hline Number of output layer units & 1 \\
\hline Momentum rate & 0.87 \\
\hline Learning rate & 0.75 \\
\hline Error after learning & 0.000055 \\
\hline Learning cycle & 30.000 \\
\hline
\end{tabular}

Tab. III The values of parameters used in neural network model.

Totally 104 data of continuous cooling tests in different conditions were collected, trained, validated and tested by means of ANNs. Among 104 experimental sets, 74 sets were randomly chosen as a training set for the ANN-I and ANN-II modeling, 15 data for validating of the results and the remaining 15 sets were used as testing the generalization capacity of the proposed models. To make a decision on the completion of the training processes, two termination states are declared: state 1 (ANN-I model) means that the training of neural network was ended when the maximum epoch of process reached (1000) while state 2 (ANN-II model) means the training ended when minimum error norm of network gained.

The performance of an ANN model mainly depends on the network architecture and parameter settings. One of the most difficult tasks in ANN studies is to find this optimal network architecture, which is based on the determination of numbers of optimal layers and neurons in the hidden layers by a trial and error approach. The assignment of initial weights and other related parameters may also influence the performance of the ANN to a great extent. However, there is no well defined rule or procedure to have an optimal network architecture and parameter settings where the trial and error method still remains valid. This process is very time consuming [39].

In this study the Matlab ANN toolbox is used for ANN applications. To overcome optimization difficulty, a program has been developed in Matlab which handles the trial and error process automatically. The program tries various numbers of layers and neurons in the hidden layers both for the first and second hidden layers when the lowest RMSE (Root Mean Squared Error) of the testing set, as the training of the testing set is achieved [40]. 
Khalaj G. et al.: Modeling the correlation between heat treatment, chemical...

\section{Results and discussion}

In this study, the error that arose during the training and testing in ANN-I and ANN-II models can be expressed as absolute fraction of variance $\left(\mathrm{R}^{2}\right)$, mean absolute error (MAE), root mean square error (RMSE), relative absolute error (RAE) and root relative squared error (RRSE).

All of the results obtained from experimental studies and predicted by using the training, validation and testing results of ANN-I and ANN-II models are given in Figs. $2 \mathrm{a}, 2 \mathrm{~b}$ and $2 \mathrm{c}$ respectively. The linear least square fit line, its equation and the $\mathrm{R}^{2}$ values have been shown in these figures for the training, validation and testing data. Also, inputs values and experimental results with validation and testing obtained from ANN-I and ANN-II models were given in Tabs. IV-VII, respectively. As it is visible in Fig. 2, the values obtained from the training, validation and testing in ANN-I and ANN-II models are very close to the experimental results. The result of testing phase in Fig. 2 shows that the ANN-I and ANN-II models are capable of generalizing between input and output variables with reasonably good predictions.

Traditional regression analysis was made with MINITABß). The regression equation is:

$$
\begin{gathered}
\mathrm{Bf}=61.7403+5034.31 \mathrm{C}-61.0772 \mathrm{Mn}+1438.76 \mathrm{Nb}+469.287 \mathrm{Mo}+25.8846 \\
\mathrm{Nbs}-0.410399 \mathrm{AT}+0.502291 \mathrm{D} \gamma+0.204974 \mathrm{CR}
\end{gathered}
$$

The $\mathrm{R}^{2}$ value is 0.62 .

The performance of ANN-I and ANN-II models is shown in Tab. VIII. The best values of $\mathrm{R}^{2}$, RMSE, RAE, MAE and RRSE are 0.9789, 0.6821, 0.2085, 0.5663 and 0.2214 , respectively all for the training set in ANN-II model. The minimum value of $\mathrm{R}^{2}$ and the maximum values of RMSE, RAE, MAE and RRSE are 0.9241, 1.3370, $0.3376,1.0495$ and 0.4061 , respectively all for validation set in ANN-I model. This shows that ANN-II model is better trained than ANN-I where the entire statistical evaluators of even testing phase of ANN-II model has higher performance than those of ANN-I training and testing sets. However, both of the models exhibit valuable results and the entire statistical values show that the proposed ANN-I and ANN-II models are suitably trained and can predict the bainite fraction values very close to the experimental ones.

\section{Conclusions}

ANNs can be an alternative approach for the evaluation of bainite fraction values of continuous cooling of HSLA steels specimens. Comparison between ANNs in terms of $\mathrm{R}^{2}$, RMSE, RAE, MAE and RRSE showed that ANNs models are capable to predict suitable results for bainite fraction values of HSLA steels specimens in the studied range. Two termination states are declared: state 1 (ANN-I model) means that the training of neural network was ended when the maximum epoch of process reached (1000) while state 2 (ANN-II model) means the training ended when minimum error norm of network gained. The entire statistical evaluators of ANN-II model has higher performance than those of ANN-I. However, both 


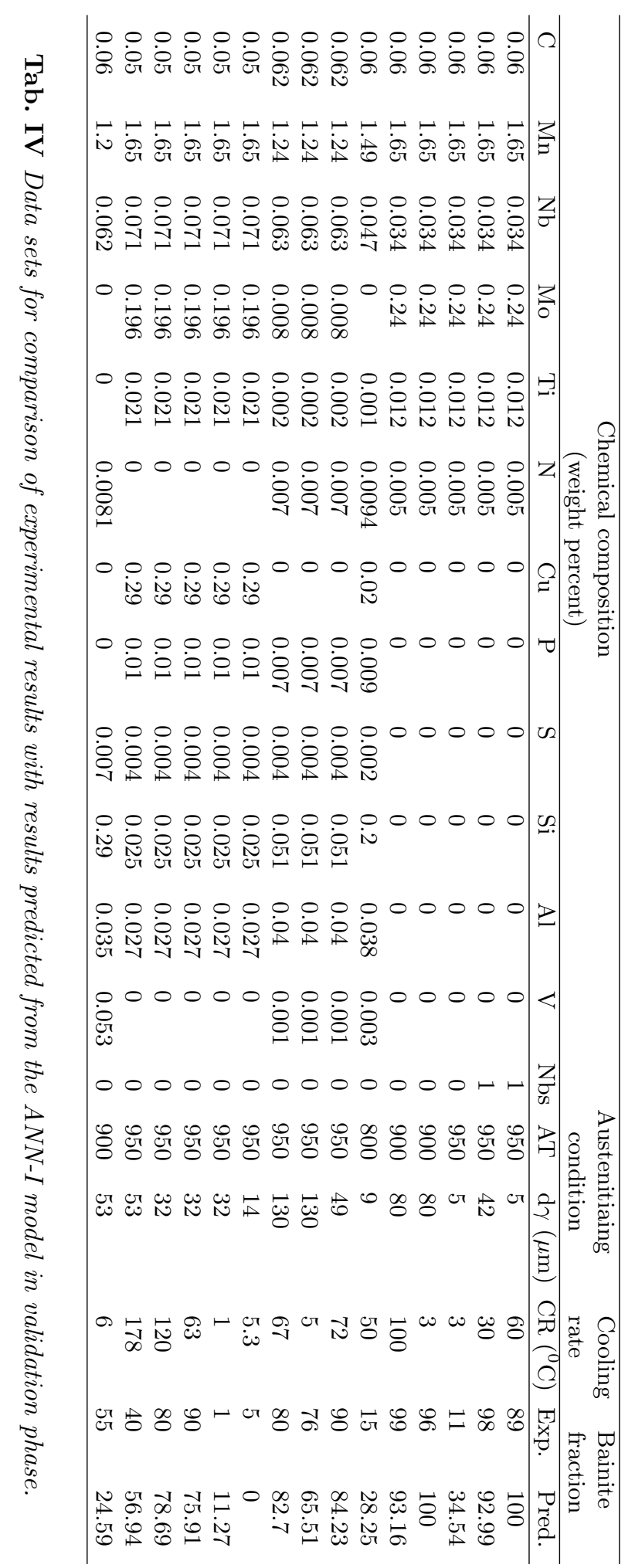


Khalaj G. et al.: Modeling the correlation between heat treatment, chemical...

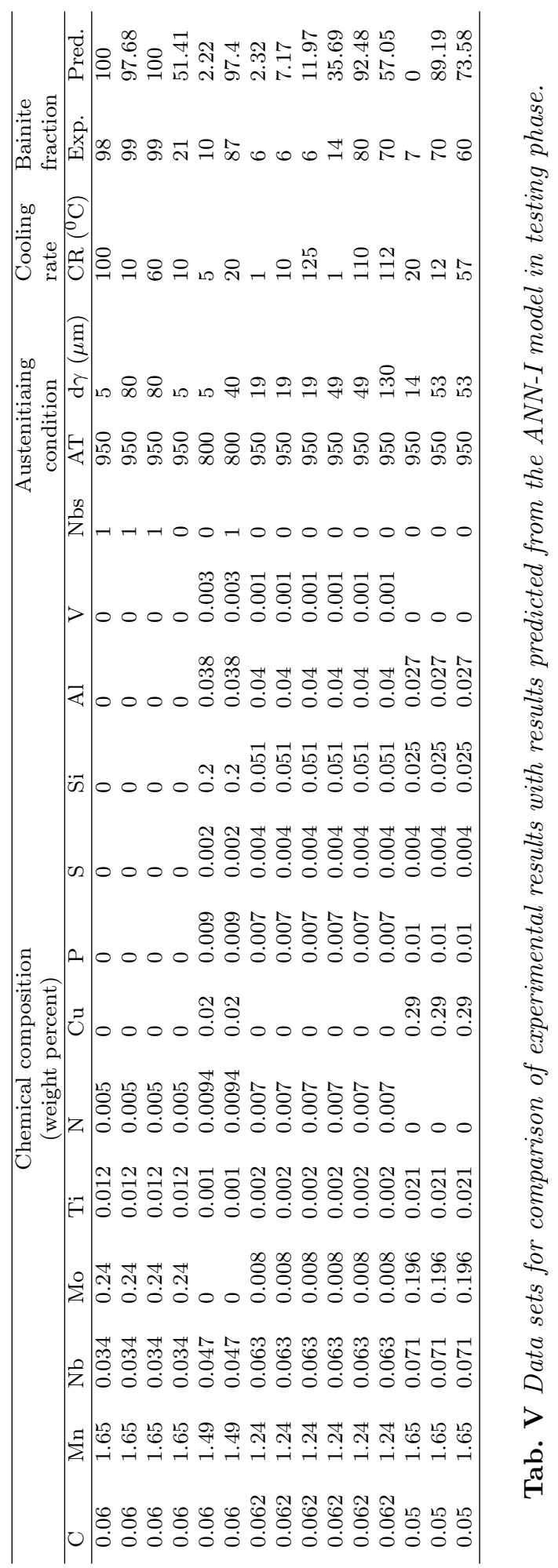




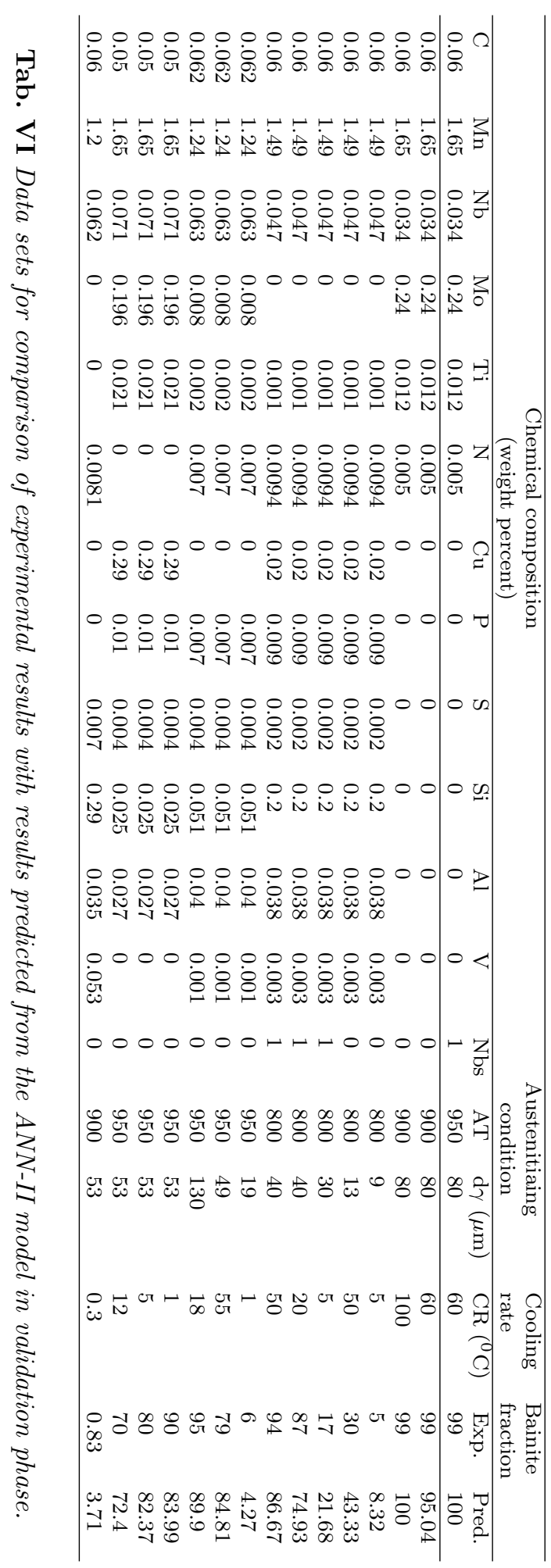


Khalaj G. et al.: Modeling the correlation between heat treatment, chemical...

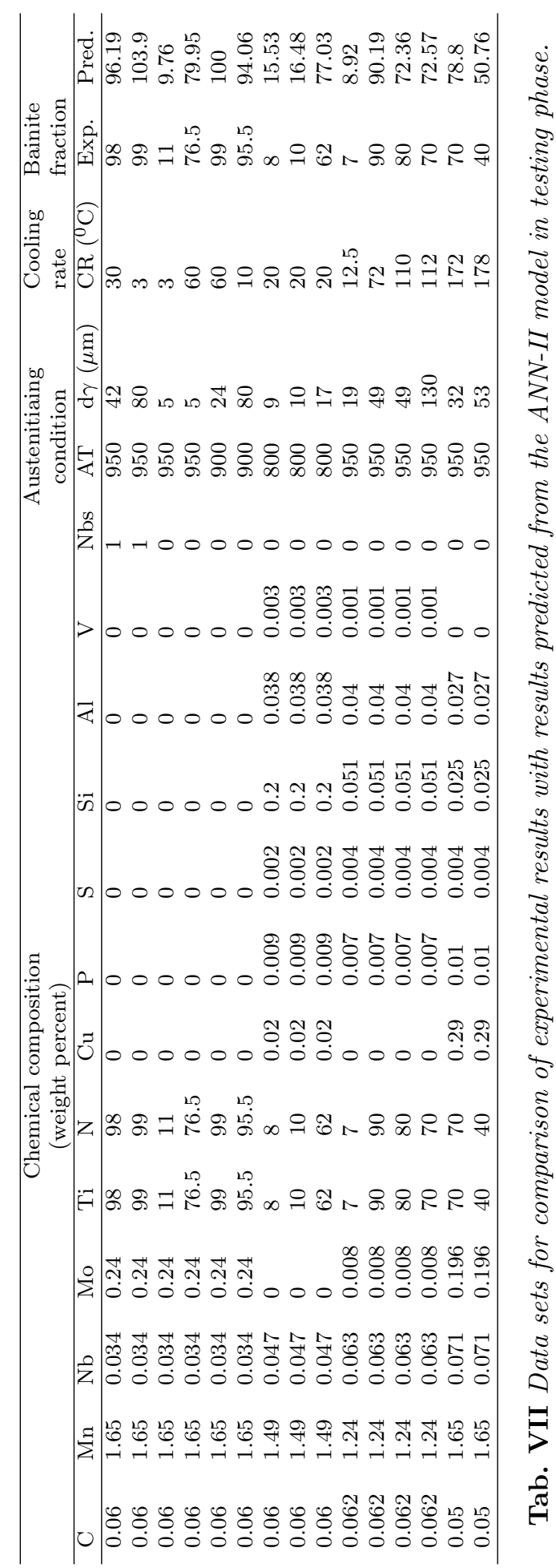




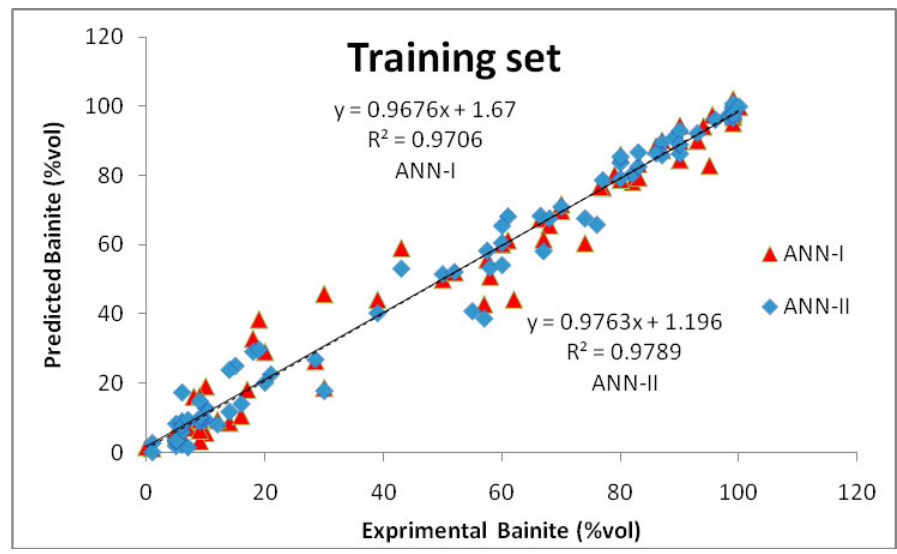

(a)

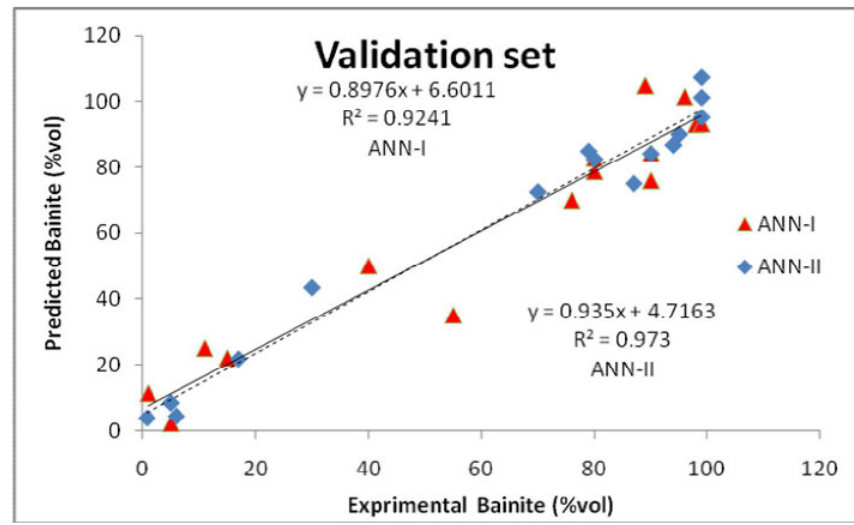

(b)

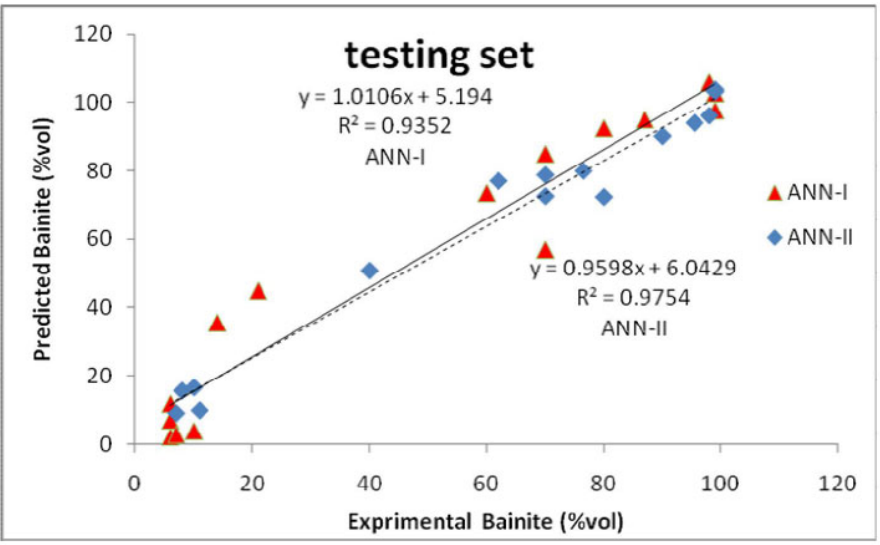

(c)

Fig. 2 The correlation of the measured and predicted bainite fraction values of HSLA steels in a) training, b) validation and c) testing phase for ANN models. 
Khalaj G. et al.: Modeling the correlation between heat treatment, chemical...

\begin{tabular}{lcccccc}
\hline & $\begin{array}{c}\text { ANN-I } \\
\text { training } \\
\text { set }\end{array}$ & $\begin{array}{c}\text { ANN-I } \\
\text { validation } \\
\text { set }\end{array}$ & $\begin{array}{c}\text { ANN-I } \\
\text { testing } \\
\text { set }\end{array}$ & $\begin{array}{c}\text { ANN-II } \\
\text { training } \\
\text { set }\end{array}$ & $\begin{array}{c}\text { ANN-II } \\
\text { validation } \\
\text { set }\end{array}$ & $\begin{array}{c}\text { ANN-II } \\
\text { testing } \\
\text { set }\end{array}$ \\
\hline R2 & 0.9766 & 0.9241 & 0.9352 & 0.9789 & 0.973 & 0.9754 \\
\hline RMSE & 0.9596 & 1.3770 & 0.8774 & 0.6821 & 0.7844 & 0.839 \\
\hline RAE & 0.2960 & 0.3376 & 0.2251 & 0.2085 & 0.2398 & 0.2565 \\
\hline MAE & 0.8042 & 1.0495 & 0.6997 & 0.5663 & 0.6512 & 0.6965 \\
\hline RRSE & 0.3114 & 0.4061 & 0.2587 & 0.2214 & 0.2546 & 0.2723 \\
\hline
\end{tabular}

$$
\begin{gathered}
R^{2}=1-\left(\frac{\sum_{i}\left(t_{i}-o_{i}\right)^{2}}{\sum_{i}\left(o_{i}\right)^{2}}\right) \quad \text { MAPE }=\frac{1}{n} \sum_{i}\left|t_{i}-o_{i}\right| \times 100 \\
R M S E=\sqrt{\frac{1}{n} \sum_{i}\left(t_{i}-o_{i}\right)^{2}} \quad R A E=\frac{\sum_{i}\left|t_{i}-o_{i}\right|}{\sum_{i}\left|t_{i}-\frac{1}{n} \sum_{i} t_{i}\right|} \\
R R S E=\sqrt{\frac{\sum_{i}\left(t_{i}-o_{i}\right)^{2}}{\sum_{i}\left(t_{i}-\frac{1}{n} \sum_{i} t_{i}\right)^{2}}}
\end{gathered}
$$

where $t$ is the target value, o is the output value and $n$ is the number of data sets in each of training and testing phases.

Tab. VIII Statistical parameters of the proposed ANN models.

of the models exhibit valuable results and the entire statistical values show that the proposed ANN-I and ANN-II models are suitably trained and can predict the bainite fraction values very close to the experimental ones.

\section{Acknowledgements}

The authors wish to thank the research board of WorldTech Scientific Research Center (WT-SRC) for the financial support and the provision of the research facilities used for this work.

\section{References}

[1] A. J. DeArdo: Microalloying'95 Conference Proceedings, Pittsburgh, USA, ISS, 1995, pp. 15-33.

[2] C. Ouchi: ISIJInt., vol. 41, 2001, pp. 542-553.

[3] J.-C. Zhao, M. R. Notis: Continuous cooling transformation kinetics versus isothermal transformation kinetics of steels: A phenomenological rationalization of experimental observations, Materials Science and Engineering R: Reports, 1995, 15 (4-5), pp. 135-208.

[4] L. G. E. Volb-ath, R. Hackl, K. G. Schmitt-Thomas, D. Daub: Microalloying '88, ASM, Metals Park, OH, 1988, 353.

[5] H. Bhadeshia: Bainite in Steels, The Institute of Materials, London, UK, 1992.

[6] R. Hehemann, K. Kinsman, H. Aaronson: Metallurgical Transactions 3A, 1972, 1077.

[7] M. Hillert, G. Purdy: Scripta Materialia. Vol. 43, 2000, 831.

[8] A. Hultgren: Transactions ASM, Vol. 39. 1947, 915.

[9] T. Minote, S. Torizuka, A. Ogawa, M. Niikura M.: ISIJIntl, 36, 201, 1996. 
[10] Report: Advanced High Strength Steel (AHSS) Application Guidelines, Version 3, Intl. Iron and Steel Institute, Committee on Automotive Application, September, 2006.

[11] H. K. D. H. Bhadeshia: Bainite in Steels: Transformations, Microstructure and Properties, edition, Maney publishing. The University Press, Cambridge, 141, 2001.

[12] G. B. Olson, H. K. D. H. Bhadeshia, M. Cohen: Acta Metall, 37, 381, 1989.

[13] G. I. Rees, J. Perdrix, T. Maurickx, H. K. D. H. Bhadeshia: Mater. ScL Eng. A, A194, 179, 1995.

[14] M . Hillert: Scripta Mater., 47, 175, 2002.

[15] H. Matsuda, H. K. D. H. Bhadeshia: Pro. Royal Soc, London, A460, 1707, 2004.

[16] F. Fazeli, M . Militzer: Mater. ScL Technol Conf, TMS, Warrendale, PA, 469, 2003.

[17] A. Borgenstam, M . Hillert: Acta Metall., 48, 2777, 2000.

[18] T. Somnail, C. Garcia-Mateo: Compu. Mater. Sci., 34, 323, 2005.

[19] M. Umemoto, A. Hiramatsu, A. Moriya, T. Watanabe, S. Nanba, N. Nakajima, G. Anan, Y. Higo: ISIJIntl., 32, 306, 1992.

[20] S. J. Jones, H. K. D. H. Bhadeshia: Acta Mater., 45, 2911, 1996.

[21] A. Samoilov, Y. Titovets, N . Zolotorevskii, G. Hribemig, P. Stiaszny: Second Intl. Conf. on Processing Materials for Properties, TMS-AIME, San Francisco, CA, 639, 2000.

[22] D. Liu, F. Fazeli, M. Mihtzer, W. J. Poole: Metall. Mater. Trans. A, 38A, 894, 2007.

[23] T. Minote, S. Torizuka, A. Ogawa, M. Niikura: ISIJIntl, 36, 201, 1996.

[24] Z. Sterjovski, D. Nolan, K. R. Carpenter, D. P. Dunne, J. Norrish: Artificial neural networks for modelling the mechanical properties of steels in various applications, Journal of Materials Processing Technology, 170, 2005, pp. 536-544.

[25] Tan Wen, Liu Zhen-yu, Wu Di, Wang Guo-dong: Artificial Neural Network Modeling of Microstructure During C-Mn and HSLA Plate Rolling, JOURNAL OF IRON AND STEEL RESEARCH, INTERNATIONAL. 2009, 16(2), pp. 80-83.

[26] G. Khalaj, T. Azimzadegan, M. Khoeini, M. Etaat: Artificial neural networks application to predict the ultimate tensile strength of X70 pipeline steels, Neural Computing and Applications, DOI 10.1007/s00521-012-1182-0.

[27] A. Nazari, G. Khalaj: Prediction compressive strength of lightweight geopolymers by ANFIS, Ceramics International, 2012, 38(6), pp. 4501-4510.

[28] G. Khalaj, H. Yoozbashizadeh, A. Khodabandeh, A.Nazari: Artificial neural network to predict the effect of heat treatments on Vickers microhardness of low- carbon Nb microalloyed steels. Neural Computing and Applications, 2013, 22(5), pp. 879-888

[29] Khalaj, G., Khoeini, M., Khakian-Qomi, M., ANN-based Prediction of ferrite fraction in continuous cooling of microalloyed steels, Neural Computing and Applications, 2012, DOI 10.1007/s00521-012-0992-4.

[30] R. Ince: Prediction of fracture parameters of concrete by artificial neural networks. Eng Fract Mech., 71(15), 2004, pp. 2143-2159.

[31] W. S. McCulloch, W. Pitts: A logical calculus of the ideas immanent in neural nets, Bulletin of Mathematical Biophysics, 5, 1943, pp. 115-137.

[32] F. Rosenblatt: Principles of neurodynamics: Perceptrons and the theory of brain mechanisms, Spartan Books, Washington, DC, 1962.

[33] D. E. Rumelhart, G. E. Hinton, R. J. William: Learning internal representations by error propagation. In: D. E. Rumelhart, J.L. McClelland (Eds.), Proceedings Parallel Distributed Processing, Foundations, vol. 1, MIT Press, Cambridge, 1986.

[34] R. Tafteh: Austenite decomposition in an X80 linepipe steel. Master's thesis, The University of British Columbia, 2011.

[35] S. Gerami: Characterization and microstructural evolution model of a $\mathrm{Nb}$ complex phase steel. Master's thesis, The University of British Columbia, 2010. 
Khalaj G. et al.: Modeling the correlation between heat treatment, chemical...

[36] P. Petkov: Austenite decomposition of low carbon high strength steels during continuous cooling. Master's thesis, The University of British Columbia, 2004.

[37] K. K. Lottey: Austenite decomposition of a HSLA-Nb,Ti steel and an A1-TRIP steel during continuous cooling. Master's thesis, The University of British Columbia, 2002.

[38] M. Olasolo, P. Uranga, J. M. Rodriguez-Ibabe, B. L'opez: Effect of austenite microstructure and cooling rate on transformation characteristics in a low carbon $\mathrm{Nb}-\mathrm{V}$ microalloyed steel. Mater. Sci. Eng. A, 528, 2011, pp. 2559-2569.

[39] G. Khalaj, A. Nazari, H. Pouraliakbar: Prediction martensite fraction of Microalloyed steel by artificial neural networks, Neural Network World, 2013, 23(2), pp. 117-130.

[40] G. Khalaj: Artificial neural network to predict the effects of coating parameters on layer thickness of chromium carbonitride coating on pre-nitrided steels, Neural Computing and Applications, 2012, DOI: 10.1007/s00521-012-0994-2 